\title{
OBITUARIO
}

\section{ROBERT A. POTASH (1921-2016)}

$\mathbf{R}$ obert Potash nació en Boston en enero de 1921 y

Rempezó con buen pie su educación en la famosa Boston Latin School, donde se graduó el primero de su clase facilitando así que continuara sus estudios en Harvard University. En 1942 se graduó Magna Cum Laude en historia, con Latinoamérica como su área de interés. Como Estados Unidos había entrado en la guerra fue movilizado por el ejército y, por fortuna, pasó el mayor tiempo en Maryland, en el Military Intelligence Center y sólo marchó a Okinawa poco antes de la rendición del Japón. Ya libre, con el rango de Master Sargeant, a principios de 1946 se casó con Jeanne Feinstein, su compañera de toda la vida. Ese mismo otoño volvió a Harvard para hacer su doctorado, del que se tituló con la tesis sobre El Banco de Avío, publicada en español por el Fondo de Cultura Económica en 1956, un libro que sigue siendo un clásico. Entró como instructor a la Universidad de Massachusetts, Amherst, donde fue ascendiendo hasta ocupar la cátedra Haring de Estudios 
Latinoamericanos. Dirigió el Departamento de Historia y el programa de la Universidad sobre Historia Argentina. Entre 1955 y 1957 trabajó en el Departamento de Estado en la División de Investigación e Inteligencia, como analista sobre la Argentina después del golpe contra Perón, lo que seguramente despertó su interés sobre el ejército argentino (Army and Politics in Argentina) y lo hizo célebre en ese país. En sus memorias ofrece muchas anécdotas sobre sus contactos con los militares.

En su libro Looking Back, My First Eighty Years, A Mostly Professional Memoir, publicado en 2008, recuerda cómo durante largo tiempo venía contemplando alguna forma de facilitar el acceso al Archivo General de Notarías de la Ciudad de México. Consultado para su estudio sobre el Banco de Avío, había tropezado con su organización cronológica bajo el nombre de los notarios, lo que dificultaba la consulta del rico arsenal para muchas y variadas ramas de la historia. En 1978, después de una larga investigación terminó el primer tomo de su estudio sobre El Ejército y la Política en Argentina, 1945-1962 y “para descansar” empezó a considerar el proyecto. Comenzaban a utilizarse las gigantes computadoras de cintas, y consultó con el director del Centro de Cómputo de su Universidad las posibilidades que ofrecía para el proyecto, pues apenas tenía nociones de lo que ofrecían las formas sofisticadas para recuperar datos. El director le informó que podía crearse un programa para capturar datos y que sería fácil ordenarlos en una Guía, de manera que lo primero que había que hacer era decidir los datos que se iban a registrar.

Ese 1978 nos encontrarnos en la reunión anual de la American Historical Association y me mencionó vagamente el 
proyecto. Cavilaba sobre el asunto y de vacaciones en Guatemala visitó el Archivo de Protocolos y vio que éste tenía la misma organización del mexicano, lo que lo convenció de que una Guía Computarizada del Archivo de Notarías de la Ciudad de México serviría de modelo para ordenar todos los archivos hispanoamericanos. En junio de 1979, Potash se reunió conmigo y con Roberto Moreno, entonces director del Instituto de Investigaciones Históricas, para plantearnos el proyecto, aunque la proposición formal me la hizo en diciembre, en la reunión de la American Historical Association, fue donde quedamos que nos reuniríamos en enero en El Colegio de México con Roberto Moreno y Jan Bazant, también conocedor del archivo. Se decidió que, como directora del Centro de Estudios Históricos, yo contrataría los auxiliares que trabajarían en el proyecto. En esa reunión Potash nos presentó el primer borrador de la cédula que utilizarían los ayudantes para buscar los datos pertinentes y elegimos los años 1829, 1847 y 1875. A mí me pareció que debíamos elegir años conflictivos y sugerí los dos primeros y 1857, año de la Ley de Desamortización, pero Bazant insistió en 1875 por la reforma de la legislación que regía el Archivo.

Su empeño, entusiasmo y buenos contactos habían logrado que la Tinker Foundation le otorgara a Potash 36000 dólares para el proyecto y que dos amigos de la Organización de Estados Americanos le concedieran 15000 dólares como complemento. Con esos elementos se echó a caminar el proyecto. El Colegio de México se hizo cargo de gastos menores, la administración de los fondos y la vigilancia del trabajo. Se inició el trabajo una vez que encontró candidatos idóneos para el trabajo. Bob mismo siguió redondeando 
el proyecto y redactó una ponencia "Los archivos notariales: cómo revelar sus tesoros escondidos” que presentó en el Segundo Congreso Mexicano de Historia Legal, organizado en 1981 por Guillermo Margadant. El Instituto canceló toda participación y Bazant, investigador solitario, nunca participó.

Debido a que mi gestión como directora terminaba a principios de 1982 y me habían otorgado una beca Guggenheim para investigar en archivos del extranjero, le pedí a Pilar Gonzalbo Aizpuru que se hiciera cargo del proyecto en mi ausencia y aunque a mi vuelta lo retomé, pronto ella pasó a ser el alma de dicho proyecto y a ella debemos su constante mejoramiento.

El Centro de Cómputo de El Colegio de México y sus diferentes autoridades nos auxiliaron, aunque el Computing Center de la Universidad de Massachusetts procesó y publicó el material; ellos contaban con una computadora impresionante que Rosa María Ruvalcaba y yo vimos durante nuestra visita en 1985. Años más tarde, cuando El Colegio de México decidió convertir las Guías impresas en $\mathrm{CD}$, se tuvo que volver a capturar la información, lo que sirvió para enriquecerla puesto que la experiencia había permitido mejorar las cédulas con datos importantes que se habían pasado por alto.

Terminado el proyecto, decidí que valía la pena seguir con la Guía que muchos investigadores empezaban a consultar. El presidente de El Colegio lo aprobó y desde entonces la Institución ha financiado su larga trayectoria, en la que sólo tuvimos un pequeño apoyo del Conacyt. Como yo estaba trabajando el centralismo, Texas y la guerra con Estados Unidos, sugerí iniciar con 1835 y llegar hasta 1847. 
Después, propuse continuar hasta la conclusión de la desamortización y la nacionalización de los bienes del clero, todo ese traslado de bienes y cerciorarnos si las conclusiones de Bazant sobre la Desamortización en la Ciudad de México se sostenían. En una de las últimas conversaciones con Potash, le mencioné que llegaríamos a 1870, según mi propuesta. Sin duda, pienso ahora, valdría la pena también volver hacia atrás, hasta 1804, para ver el efecto de la aplicación de la Convalidación de Vales Reales.

En realidad, yo había conocido a Robert y Jeanne Potash en el verano de 1965 en Harvard University, porque decidí tomar un curso que ofrecía sobre México, Brasil y Argentina. Mi pertenencia a El Colegio de México nos acercó. Cuando vi que en sus memorias mencionaba una cena a la que los invitamos, me di cuenta de que había llevado un Diario. Nos volvimos a encontrar en la Tercera Reunión de Historiadores Mexicanos y Norteamericanos, convocada por don Daniel Cosío Villegas en Oaxtepec, Morelos. Los dos fuimos invitados a ser ponentes sobre historias generales de México en versiones en inglés y en español. La aparente poca importancia de la sesión hizo que nos dieran un salón muy pequeño del Centro Vacacional de IMss. Curiosamente, en esa sesión a la que acudieron don Daniel, don Edmundo O'Gorman, Stanley Ross, Alistair Hennessy y algunos otros historiadores conocidos que no recuerdo, y para colmo, algunos periodistas y donde se discutió mi ponencia, sirvió para que esa serie de periodicazos que se inició con un "Los historiadores contra e Libro de Texto" a ocho columnas terminara con la decisión del secretario de Educación de suspender el coctel en honor de los invitados en el Castillo de Chapultepec. Don Daniel Cosío publicó una carta 
al señor Agustín Yañez explicando el entuerto, con la aclaración y los límites de la discusión, pero no hubo cambios.

Robert Potash y yo seguimos encontrándonos en reuniones académicas, en especial las anuales de la American Historical Association a las que yo asistía puntualmente para mantenerme al día. Cuando lo eligieron para presidir la reunión anual de la Conference of Latin American Historians, me invitó a ofrecer el discurso de la sesión inaugural que titulé, "México y Estados Unidos desde el Foreign Office". Sus numerosos viajes a México para vigilar el proyecto cesaron cuando inició sus investigaciones en Argentina. Todavía nos vimos en dos ocasiones más, porque los dos dejamos de asistir a las reuniones anuales de la American Historical Association, aunque mantuvimos comunicación para estar al día de buenas y malas noticias. Me envió sus tres tomos del estudio del ejército y aunque hice planes para visitarlos en Amherst, lamento no haberlos concretado. La nota de Jeanne con la mala noticia, me causó gran tristeza. Robert Potash fue un gran historiador y un gran amigo. Tuvo especial gratitud con El Colegio de México y en especial por el Centro de Estudios Históricos, donde en el proyecto de Notarías deja un gran recuerdo. Descanse en paz.

Josefina Zoraida Vázquez El Colegio de México 